\title{
Ileal impaction resolution in a horse with colic via a standing right flank laparotomy - case report
}

\author{
[Laparotomia de equino em estação para resolução de compactação \\ de íleo - relato de caso] \\ J.A. Arantes ${ }^{1}$, G.M. Reginato ${ }^{1}$, R.G.S. Dória ${ }^{2 *}$ \\ ${ }^{1}$ Aluno de pós-graduação - Faculdade de Zootecnia e Engenharia de \\ Alimentos - Universidade de São Paulo - Pirassununga, SP \\ ${ }^{2}$ Faculdade de Zootecnia e Engenharia de Alimentos - Universidade de \\ São Paulo - Pirassununga, SP
}

\begin{abstract}
This report describes a horse presenting ileal impaction that went through a right flank laparotomy procedure while standing. The decision to use this technique was made under the influence of several factors: the patient exhibited a calm temperament and demonstrated responsiveness to the analgesic treatment for pain control; the abdominal lesion was amenable to correction by a standing right flank approach. Also, the owner reported financial problems. Ileal obstruction was relieved successfully, and the horse recovery was satisfactory. This case highlights that, in specific cases of colic syndrome, the use of surgical procedures in the standing position might be a viable option and promote fast recovery.
\end{abstract}

Keywords: equine, colic syndrome, ileus, standing procedure, flank surgery

\section{RESUMO}

Este relato de caso descreve um equino com compactação de íleo corrigida por laparotomia em estação pelo flanco direito. A decisão dessa abordagem foi influenciada por vários fatores: o paciente exibiu um temperamento calmo e demonstrou responsividade ao tratamento analgésico para controle da dor; a afecção intestinal em questão foi passível de correção pela abordagem pelo flanco direito em estação; $e$ o proprietário relatou limitações financeiras. A desobstrução ileal foi realizada com sucesso e o cavalo apresentou recuperação satisfatória. Este caso destaca que, em casos específicos da síndrome de cólica, o uso de um procedimento em estação pode ser uma abordagem viável e promover uma rápida recuperação.

Palavras-chave: cavalo, síndrome de cólica, ileus, cirurgia em estação, cirurgia pelo flanco

\section{INTRODUCTION}

Obstruction of the small intestine is an acute abdominal condition that can occur in horses and notably, the ileum is the most common section involved in these cases of intraluminal impaction (Fleming and Mueller, 2011). The main causes include feed obstruction that can be related to poor dentition and consequently poor mastication; it may also occur due to luminal obstruction or narrowing, typically at the ileo-caecal orifice and these cases are frequently associated with tapeworm burdens (Little and Blikslager, 2002).

Ileal impactions often exhibit mild to severe degrees of colic and are slowly progressive (Mueller and Fleming, 2009); intestinal borborygmi may occur and analgesics are initially effective for pain relief (Fleming and Mueller, 2011). Enterogastric reflux may be absent in the initial stages of the disease, as well as in dehydrated animals, however, this clinical sign can be seen in later stages of the disease (Mueller

Recebido em 7 de outubro de 2019

Aceito em 9 de março de 2020

*Autor para correspondência (corresponding author)

E-mail: redoria@usp.br 
and Fleming, 2009). Initially, distension of the small intestines may not be palpated in a rectal examination; however, with disease progression, loops of distended small intestine can be palpated in the right dorsal quadrant of the abdomen. Occasionally, a firm, smooth ileum surface may be detected, originated from the base of the cecum and coursing from the right side of midline obliquely downward, cranial, and to the left side. On ultrasonography, the small intestine may appear distended and not presenting peristaltic movements (Mueller and Fleming, 2009).

When small intestinal obstruction is not resolved with medical support, surgical intervention is needed to avoid progressive hypovolemia and systemic disease associated with ongoing gastric reflux and colic (Hanson et al., 1998; Singer and Smith, 2002). When surgical treatment is suggested, a ventral midline approach is preferable because it offers improved surgical access to the abdomen (Freeman 2008). However, access through the flank can be useful in specific situations, such as those involving patients with a calm temperament, as well as those in which pain is responsive to analgesics (Graham and Freeman, 2014; Ross, 1991). If a simple ileal obstruction is detected in a patient, a manual decompression through a surgical approach via flank in the standing position might be a useful, lifesaving and less expensive alternative. This report describes a successful standing flank laparotomy performed in a horse with ileal impaction, including the advantages, prerequisites, and risks involved.

\section{MATERIAL AND METHODS}

A 17-year-old equine gelding of undefined breed who was routinely fed good-quality forage showed signs of colic. The horse was up to date on deworming program. Initial physical examination revealed tachycardia ( 68 beats per minute $[\mathrm{bpm}]$ ), tachypnoea (48 breaths/minute), a capillary refill time of 4 seconds, congestion of the oral mucous membrane with hyperemic perialveolar gingiva, intestinal hypomotility, apathy, and several superficial skin ulcers. During rectal examination, the caecum and colon were correctly positioned, but showing distension with soft consistency ingesta and no palpable small intestines. Although abdominal ultrasound was unavailable, peritoneal fluid was not collected considering the high risk of enterocentesis.
Treatment began with the placement of nasogastric tubing and continuous parenteral fluid therapy with lactated Ringer's solution (20ml/kg/h) (Ringer lactato, Sanobiol Laboratory, Ltd., Brazil). Enteral water replacement was attempted but it was unsuccessful because liquid remained in the stomach without progression. Thus, the animal was treated with an intravenous infusion of lidocaine (bolus, $1.3 \mathrm{mg} / \mathrm{kg}$ and maintenance, $0.05 \mathrm{mg} / \mathrm{kg} / \mathrm{min}$ ) (Lidovet, Bravet, Ltd., Brazil), metoclopramide $(0.04 \mathrm{mg} / \mathrm{kg} / \mathrm{h}$ bwt i.m.) (Noprosil, Isofarma Pharmaceutical Industry, Ltd., Brazil), and sorbitol (70\%) (3ml/kg bwt i.v.) (Sedacol, Calbos, Ltd., Brazil) in order to improve pain control, motility, and laxative effect, but any expected improvements were seen.

Three hours later, a second rectal examination was performed, in which distended loops of small intestine were palpable throughout the cavity. At that time, the owner was informed of the need to move the horse for a veterinary hospital with a surgical center. However, this was not possible due to the owner's financial limitations.

Therefore, the animal remained under clinical treatment. After 8 hours, the horse had 8 liters of reflux per hour; thus, a third rectal examination was performed, during which the distended, palpable small intestine persisted and an area with firm impaction was identified in a segment of the small intestine near the cecum. Considerations and risks regarding the standing abdominal surgery were discussed with the owner, who authorized the surgery when the horse's condition was worsening.

Prior to the procedure, the horse received ceftiofur (4.4mg/kg bwt i.v.) (Minoxel, Elanco, Ltd., Brazil) and flunixin meglumine $(1.1 \mathrm{mg} / \mathrm{kg}$ bwt i.v.) (Niglumine, Ceva, Ltd., Brazil). After the horse had been placed in a stock, sedation was performed with xylazine $10 \%(0.5 \mathrm{mg} / \mathrm{kg}$ bwt i.v.) (Equisedan, J.A. Health Animal, Ltd., Brazil), followed by a continuous infusion of $1 \mathrm{mg} / \mathrm{kg} / \mathrm{h}$ of xylazine $10 \%$. An inverted L block with lidocaine $2 \%(100 \mathrm{~mL})$ was used to anaesthetize the surgical area on the right flank.

Extensive clip, rigorous antisepsis, appropriate surgical draping with a commercial laparotomy sheet (Campo cirúrgico estéril descartável, Esterili-Med Industry, Ltd., Brazil) and donning of appropriate surgical apparel were performed. 
Then, a $12 \mathrm{~cm}$ vertical skin incision was made in the central region of the right paralumbar fossa, approximately $5 \mathrm{~cm}$ ventral to the lumbar transverse process and midway between the tuber coxae and the eighteenth rib. This was followed by blunt dissection of the external abdominal oblique, internal abdominal oblique and transverse abdominal muscles, as well as opening the peritoneum. These procedures allowed access to the small intestine, which was palpated blindly until the impacted segment was located. The distal region of the ileum was gently and partially exteriorized, in order to minimize risks of injury and/or bowel rupture, and then evaluated (Figure $1)$; notably, it showed regions of petechiae and $30 \mathrm{~cm}$ of firm contents.

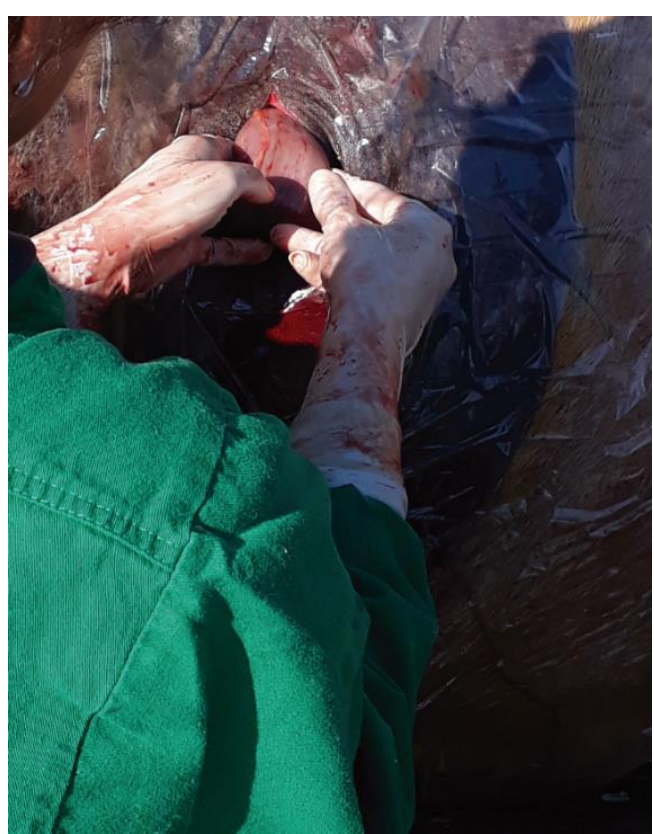

Figure 1. A side view of the horse's right flank with partial exposure of the impacted ileal segment during standing laparotomy.

Subsequently, an intercalated process was initiated, comprising intraluminal infusion of Ringer's lactate solution in the exteriorized ileum, followed by intra-abdominal massage of the impacted ileal mass to minimize mesenteric tension. A total of 2 liters of Ringer's lactate solution was infused, and decompression of the ileum was achieved. A combination of intraabdominal massage and direct infusion of saline via a 19-gauge needle into exteriorized portions of ileum were used to re-suspend the impaction before it was decompressed through the ileocecal orifice. After complete clearance of the obstruction, there were no signs of ileocecal narrowing or stenosis, nor of ileal hypertrophy. The intestinal motility was gradually becoming normal and the organ was returned to the abdominal cavity. The horse did not demonstrate pain or a visible reaction to manipulation of the intestine throughout the operation.

The body wall was closed in three layers, using simple, interrupted, cruciate-pattern sutures in the transverse abdominal, internal abdominal oblique, and external abdominal oblique muscles; Cushing pattern sutures in the sub-cutis; and simple, interrupted sutures in the skin (Figure 2). Size 2 metric polyglactin 910 (Shalon, 2, PolySuture Industry and Comerce, Brazil) was used in the muscles; size 1 metric polyglactin 910 (Shalon, 1, PolySuture Industry and Comerce, Brazil) was used in the sub-cutis; and size 1 metric polyamide was used in the skin. The surgical procedure was completed within 1 hour.

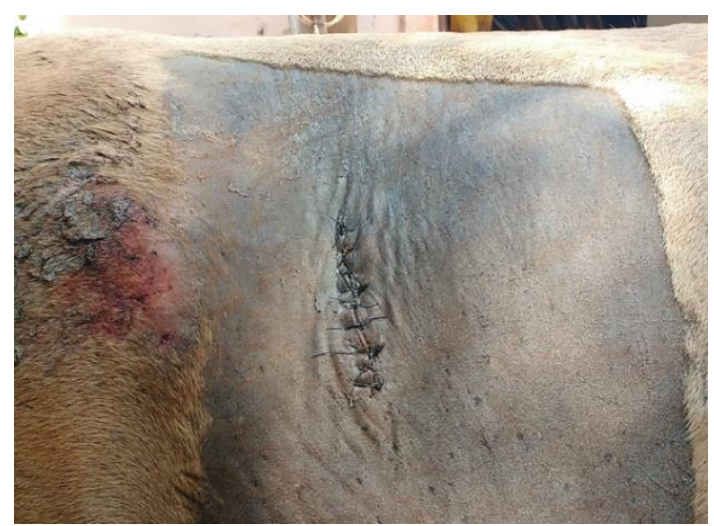

Figure 2. A side view of the horse's right flank post-laparotomy, demonstrating surgical skin wound closure with a single-point stitched suture pattern.

The horse showed no signs of enterogastric reflux and demonstrated a regular heart rate $(40 \mathrm{bpm})$ at 6 hours after surgery. Physical examinations and suture cleaning procedures with chlorhexidine solution and a series of hemograms were performed daily. Dental alterations were identified, which prevented adequate occlusal adjustment; therefore, odontoplasty was recommended after resolution of the current complaint.

Flunixin meglumine was used as an antiinflammatory and analgesic, at doses of $1.1 \mathrm{mg} / \mathrm{kg}$ 
for 3 days and $0.5 \mathrm{mg} / \mathrm{kg}$ for two additional days. Antibiotic therapy with ceftiofur $(4.4 \mathrm{mg} / \mathrm{kg}$ bwt i.v.) was maintained for a period of 9 days. Clinical assessments of the horse were within normal limits, except for hyperthermia $\left(38.6 \pm 0.2^{\circ} \mathrm{C}\right)$ on days 2 and 3 after the surgical procedure. The leukocyte count was normal $(7,600 / \mu \mathrm{L})$ after 1 postoperative day, then indicated leukocytosis $(16,300 / \mu \mathrm{L})$ on postoperative day 4 ; it then returned to normal $(11,800 / \mu \mathrm{L})$ on postoperative day 8 with no clinical signs of peritonitis (Grondin and Dewitt, 2010). Feeding was gradually initiated at 12 hours postoperative with grass in small amounts four times per day; the horse returned to its previous forage diet at the $2^{\text {nd }}$ day postoperative (Figure 3 ).

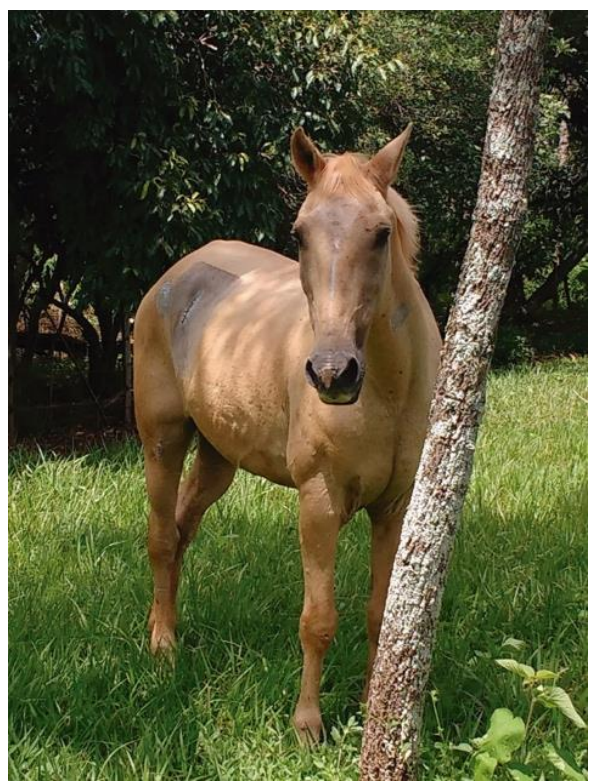

Figure 3. The horse is shown in paddock 2 days after standing exploratory laparotomy procedure through the right flank due to ileal impaction.

The horse showed no evidence of discomfort. Three days after surgery, a slight wound dehiscence occurred and emphysema was observed around the surgical wound, accompanied by subcutaneous secretions. The sutured portion of the wound healed, and the skin sutures were removed within 10 days. A portion of the un-sutured wound healed by secondary intention 20 days postoperatively. Two months after the surgical procedure, the horse had returned to routine activities with no evidence of colic or exercise intolerance.

\section{DISCUSSION}

This report describes ileal impaction in a grazing horse. Considering the odontological changes exhibited by this horse, improper chewing (despite a high-quality diet) may have resulted in larger dietary particles that accumulated in the narrow sections of the intestine, causing intraluminal impaction (Little and Blikslager, 2002).

The decision to keep a horse with colic in a medical therapy or determine that it needs surgical intervention can often be complex. However, Mueller and Fleming (2009) reported that, when enterogastric reflux is persistent, the small intestine exhibits progressive distention and the resulting pain is unresponsive to analgesics, the animal is a strong candidate for surgery. In the present case, the horse notably showed the first two symptoms, as well as apathy, tachycardia, and tachypnoea; in addition, the animal also showed signs of systemic inflammatory response syndrome (Moore and Vandenplas, 2014). Therefore, if the condition had not been resolved quickly, the animal was at increased risk of mortality (Fleming and Mueller, 2011).

Usually, when surgical intervention is needed the preferred surgical approach would be the midline exploratory celiotomy (Mueller and Fleming, 2009). This procedure is more often performed at adequately equipped surgical centers with the horse in the dorsal decubitus position under general inhalation anesthesia, using an incision through the ventral midline. This provides increased access for inspection and manipulation of the abdominal viscera, in addition to a longer duration of anesthesia and complete muscle relaxation (Freeman, 2008; Graham and Freeman, 2014). Laparotomy with flank access in horses is typically recommended for ovariectomy, as well as for resolution of uterine torsions. It is also suggested for biopsies, nephrectomy, and ureterostomy. Flank laparotomy for the surgical treatment of acute abdominal conditions is indicated in select acute abdominal conditions, such as enteroliths, incarceration of the colon in the nephrosplenic space, closure of the nephrosplenic space, and colostomy for treatment of a rectal tear (Graham and Freeman, 2014), as well as ileum impaction (demonstrated in the present case report). Moreover, flank laparotomy may be implemented in standing procedures when 
the cost or medical concerns cannot be as big as when a general anesthesia is necessary.

Exposure through a flank incision is restricted by the size of the paralumbar space, as well as by the horse's tolerance for pain associated with visceral manipulation (Ross, 1991; Howes et al., 2017). The right flank approach allows access to a few structures within the gastrointestinal tract (e.g., jejunum, ileum, cecum, right dorsal and ventral colon, and small colon and rectum); thus, the jejunum, proximal ileum, pelvic flexure, and apex of the cecum may be exteriorized safely (Graham and Freeman, 2014). The present case revealed that this access can be used to resolve ileal impaction, when the animal is responsive to analgesics; thus, the procedure can be performed while the animal remains in a standing position under the effects of tranquilizers and local infiltrative anesthesia (Graham and Freeman, 2014). It is important to emphasize that intraabdominal intestine manipulation minimizes pain by reducing mesenteric traction; moreover, it ensures adequate intestine lubrication and reduces the risk of complications, such as contamination and evisceration. However, these benefits are lost if the horse jumps the stock or falls (Howes et al., 2017).

In the present case, the choice of a standing surgery was supported by the patient's calm temperament and no severe colic, as well as the authors' reasonable preoperative confidence that the cause of colic was ileal impaction, based on the rectal examination. Although standing flank surgery is not ideal, it can be appropriate for horses with amenable abdominal lesions that can be corrected by this technique (Ross, 1991). The present case involved an uncomplicated execution of a surgical procedure, in which the impacted mass within the ileum was diluted and massaged into the cecum in a short period of time, thereby ensuring resolution of the condition without compromising the viability of the intestine. The viability might have been compromised if clinical treatment had been chosen. However, possible limitations of surgical treatment should be considered; these include exteriorization of the impacted compromised ileum through a small flank incision or a pathologically narrowed ileocecal orifice associated with a worm infestation, which would be unlikely to be surgically resolved in a standing horse.
Abdominal access through the flank may be beneficial for the reduction of pressure on the incision, due to the weight of the viscera; this is beneficial for the healing process, postoperative recovery and an earlier return to activities, while reducing the incidence of hernias in comparison to the ventral midline incision (Dukti and White, 2009).

However, it is well known that horses tend to present peritonitis, thus, adequate surgical preparation is needed, particularly for celiotomies performed in the field (Hyllyer and Wright, 1997). A wide clip, rigorous antisepsis, placement of appropriate surgical drapes around the animal, and surgeon's apparel are required, in addition to the use of sterile surgical materials. In the present case, the animal exhibit slight wound dehiscence, but did not show clinical peritonitis.

Although candidates for acute abdominal surgery should be selected carefully, when this surgical approach is indicated and performed in accordance with the precepts of surgical technique, extremely satisfactory results can be achieved, as was shown in the present case.

\section{ACKNOWLEDGMENTS}

The São Paulo Research Foundation (FAPESP) for financial support.

\section{REFERENCES}

DUKTI, S.; WHITE, N. Surgical complications of colic surgery. Vet. Clin. N. Am. Equine Pract., v.24, p.515-534, 2009.

FLEMING, K.; MUELLER, E. Ileal impaction in 245 horses: 1995-2007. Can. Vet. J., v.52, p.759763, 2011.

FREEMAN, D.E. Surgical exploration and manipulation. In: WHITE, N.A.; MOORE, J.N.; MAIR, T.S. (Eds.). The equine acute abdomen. Jakson: Teton Newmedia, 2008, p.452-472.

GRAHAM, S.; FREEMAN, D. Standing diagnostic and therapeutic equine abdominal surgery. Vet. Clin. Equine, v.30, p.143-168, 2014.

GRONDIN, T.M.; DEWITT, S.F. Normal hematology of the horse and donkey. In: WEISS, D.; WARDROP, J. 6.ed. Schaml's veterinary hematology. Hoboken: Wiley-Blackwell, 2010, p.821-829. 
HANSON, R.R.; WRIGHT, J.C.; SCHUMACHER, J. et al. Surgical reduction of ileal impactions in the horse: 28 cases. Vet. Surg., v.27, p.555-560, 1998.

HOWES, D.A.; KERR, T.A.; MCQUILLAN, R. et al. Successful small intestinal resection and anastomosis in a late term broodmare with colic via a standing left flank laparotomy. Equine Vet. Educ., v.30, p.531-535, 2017.

HYLLYER, M.H.; WRIGHT, C.J. Peritonitis in the horse. Equine Vet. Educ., v.3, p.136-142, 1997.

LITTLE, D.; BLIKSLAGER, A.T. Factors associated with development of ileal impaction in horses with surgical colic: 78 cases (1986-2000). Equine Vet J. v.34, p.464-468, 2002.
MOORE, J.N.; VANDENPLAS, M.L. Is it the systemic inflammatory response syndrome or endotoxemia in horses with colic? Vet. Clin. Equine. v.30, p.337-351, 2014.

MUELLER, P.O.E.; FLEMING, K. Ileal impaction. In: SPRAYBERRY, K.A.; ROBINSON, N.E. Current therapy in equine medicine. 6.ed. Philadelphia: Saunders Elsevier. 2009, p.402-404.

ROSS, M.W. Standing abdominal surgery. Vet. Clin. N. Am.: Equine Pract, v.7, p. 627-639, 1991.

SINGER, E.R.; SMITH, M.A. Examination of the horse with colic: is it medical or surgical? Equine Vet. Educ., v.14, p.87-96, 2002. 